increase in world population and the desire for all to increase their standard of living. During this time, the major source of energy is projected to remain hydrocarbon fuels - oil, gas, and coal. Indeed, these fuels are expected to supply around $80 \%$ of the energy in 2030 . The global endowments of oil, gas, and coal are considered to be ample to supply the world with fuel in most of the 21 st century. However, to meet demand, the energy industry will need technology improvements and will need to improve how it burns or uses fossil fuels to reduce $\mathrm{CO}_{2}$ emissions. Constraints that could affect such efforts and, thus, the supply of energy in the future, consist of environmental concerns, manpower limitations, technical issues, restrictions on access to the deposits, and availability of the capital needed to fund the projects. Technology improvements in materials, such as polymers, chemicals, propping agents, metals, composites, and electronics, must occur in areas where steam injection is required and in deep high-pressure, high-temperature reservoirs in order for the needed energy resources to be obtained in an environmentally acceptable manner.

\section{References}

1. Facing the Hard Truths about Energy-A Comprehensive View to 2030 of Global Oil and Natural Gas, (National Petroleum Council, Washington, DC, 2007); www.npc.org (accessed January 2008).

2. World Energy Outlook 2006, (International Energy Agency, Paris, 2007); www.iea.org (accessed January 2008)

3. C.J. Campbell, The Coming Oil Crisis (Multi-Science Publishing, Essex UK, 1997).

4. J.A. Masters, AAPG Bull. 63 (2), 152 (1979).

5. H.-H. Rogner, "An Assessment of World Hydrocarbon Resources" (WP96-26, IIASA, Laxenburg, Austria, May 1996).

\title{
Methane Hydrates: An Abundance of Clean Energy?
}

\section{B.B. Rath (Naval Research Laboratory, USA)}

The discovery that gas hydrates (also called clathrate hydrates) can crystallize (Figure 1) as a solid by the combination of water and several types of gases exposed to low temperatures and elevated pressure goes back to the 1800s. French researchers were the first to report the formation of methane, ethane, and propane hydrates. ${ }^{1}$ Results of these studies remained as scientific novelties until the mid-1930s, when it was discovered in Germany that gas hydrates forming as solids above $0^{\circ} \mathrm{C}$ in gas pipelines blocked the flow of natural gas. ${ }^{2}$ This observation initiated a flurry of activities both in Europe and in the

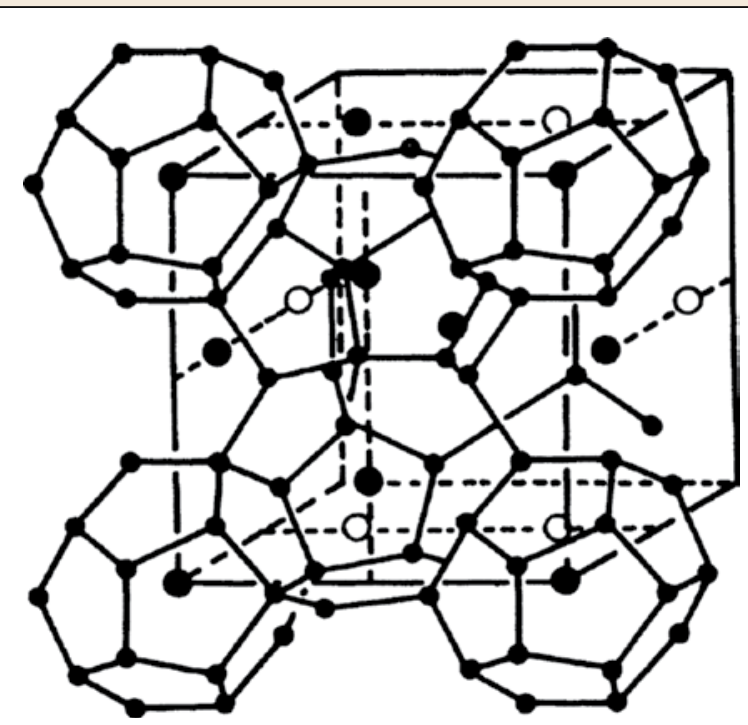

Figure 1. Crystal structure of hydrate composed of methane and water. The caged hydrate molecule aggregates into a cubic unit cell.
United States to find various inhibitors to prevent hydrate formation in gas transmission lines. During the mid-1960s, it was recognized that nature, over millions of years, has deposited vast amounts of methane hydrates along most of the continental margins in the ocean sediments, as well as along the permafrost regions in Alaska, Canada, and Russia. ${ }^{3}$ Figure 2 shows the presence of methane hydrate deposits in the ocean sediments and in the permafrost regions of the world. These deposits are byproducts of microbial decomposition of organic matter or of Earth's geothermal heating distributed worldwide where temperature and pressure are suitable for hydrate formation. The distribution of organic carbon in Earth's crust as methane

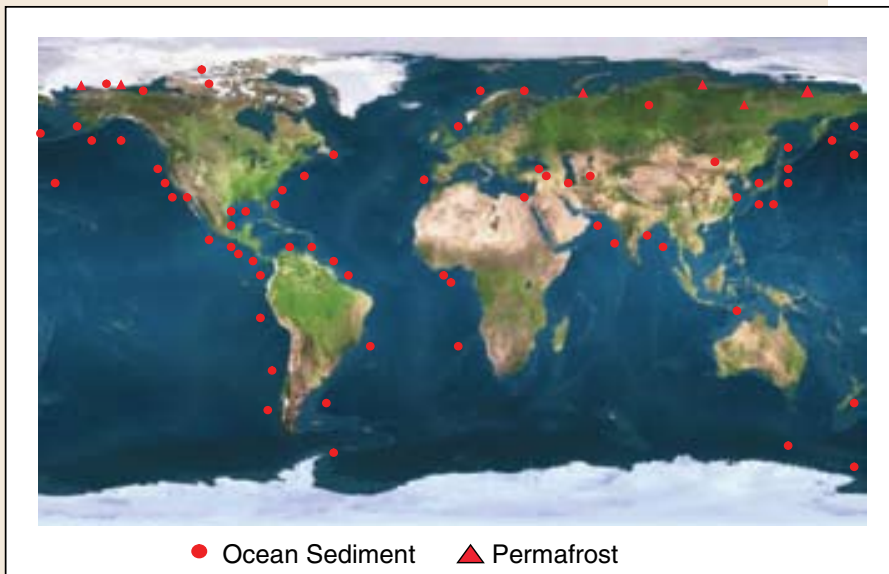

Figure 2. Global distribution of confirmed or inferred gas hydrate sites, 1997 (courtesy of James Booth, U.S. Geological Survey). This information represents our very limited knowledge. Gas hydrate is probably present in essentially all continental margins. 
hydrates along the oceans and the permafrost regions is estimated to be more than twice that contained in recoverable and nonrecoverable fossil fuel (including coal, oil, and natural gas). Figure 3 shows the distribution of organic carbon in Earth's crust in gigatons. If extracted from the ocean sediments, the $>160 \mathrm{~m}^{3}$ of methane trapped in each cubic meter of hydrate constitutes a large deposit of an alternate energy source. Although the technology for safe extraction of methane from these deposits in the oceanic sediments along the continental margins is yet to be developed, there is currently an international collaboration-involving Japan, Canada, the United States, Germany, and India - on the Mallik Wells in the Mackenzie Delta in northern Canada. The investigators are focusing on developing methods to mine this energy from the permafrost regions.

The United States Geological Survey (USGS) estimates the resource potential of methane hydrates in the United States alone to be about 200,000 trillion cubic feet (tcf) (i.e., 5,600 trillion cubic meters, tcm). The current annual consumption of natural gas is about $22 \mathrm{tcf}(0.62 \mathrm{tcm})$. Figure 4 shows the geographic locations of methane hydrate deposits along the U.S. coastal margins. According to these estimates, at about $1 \%$ recovery, the deposits have the potential to fill the natural gas needs of the United States, at the present rate of consumption, for the next 100 years. Additionally, for direct fuel combustion, methane not only provides high energy density per weight, but also emits a minimal amount of $\mathrm{CO}_{2}$ as a byproduct compared to gasoline and coal.

Although a great deal of research is under way to understand the nature of hydrate deposits in the oceans and the permafrost regions, the safe and economical extraction of methane from hydrate fields needs thorough development. Leading efforts are being conducted by Japan along the Nankai Trough, an area identified by researchers at the United States Naval Research Laboratory (NRL), and by an international consortium along the Canadian Arctic. Several other programs are also developing around the world. The USGS and the NRL, along with the U.S. Department of Energy laboratories and universities, are engaged at a number of ocean sites along the U.S. continental margins to evaluate the extent of hydrate fields and methane gas cavities and the nature and properties of the sediment. India, in collaboration with the USGS, invested in a large survey of their coastal waters during the summer of 2006. NRL researchers have developed collaborations with Chilean and New Zealand researchers that have resulted in several expeditions in their coastal waters focused on methane hydrates as an energy source. Unsubstantiated information indicates that China is also engaged in exploration.

Many gas hydrates are stable in the deep ocean conditions, but methane hydrate is by far the dominant type, making up $>99 \%$ of gas hydrates naturally occurring on the ocean floor. The methane is almost entirely derived from microbial methanogenesis, predominantly through the process of carbon dioxide reduction. In some areas, such as the Gulf of Mexico, other thermogenically formed hydrocarbon gases also create gas hydrates, as well as other clathrate-forming gases such as hydrogen sulfide and carbon dioxide. Such gases escape from sediments at depth, rise along faults, and form gas hydrates at or just below the seafloor, but on a worldwide basis, these are of minor volumetric importance compared to methane hydrate.

The physical conditions for methane hydrate formation are found in the deep sea, commonly at water depths greater than about $500 \mathrm{~m}$ or somewhat shallower (about $300 \mathrm{~m}$ ) in the Arctic, where the bottom-water temperature is colder. Gas hydrate also forms beneath permafrost on land in arctic conditions, but by far, most natural gas hydrate is stored in the ocean floor deposits. A simplified phase diagram is shown in Figure 5,

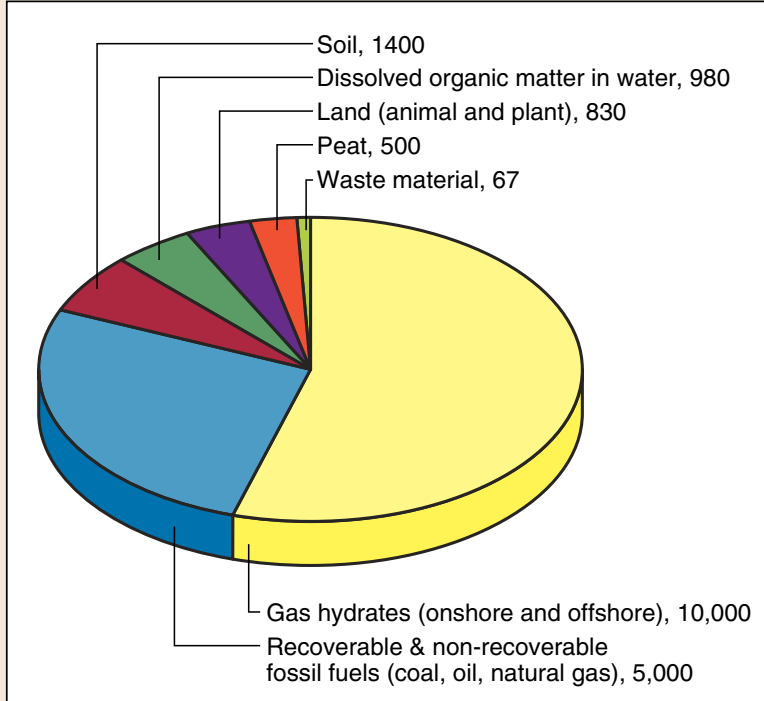

Figure 3. Distribution of organic carbon in Earth's crust in gigatons.

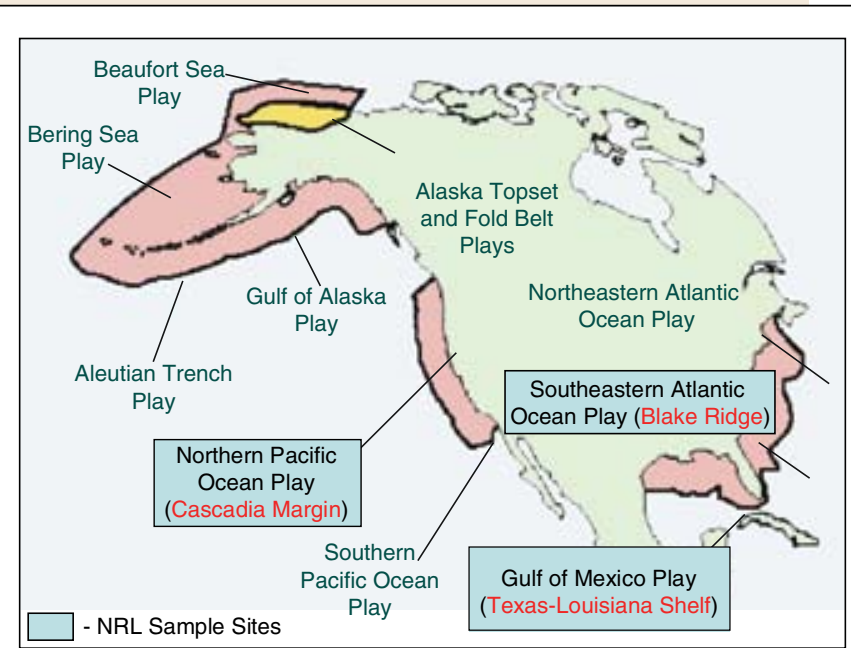

Figure 4. Geographic locations of hydrates along the U.S. coastal regions. NRL is the Naval Research Laboratory. (See Reference 4.) Note: A "play" is a group of fields with similar trap structures and reservoir rock.

in which pressure has been converted to water depth in the ocean (thus pressure increases downward in the diagram). The curving dashed line is the phase boundary, separating conditions in the temperature/pressure field where methane hydrate is stable to the left of the curve from conditions where it is not (to the right). Near the ocean surface, temperatures are too warm and pressures too low for methane hydrate to be stable. Temperature decreases with depth, and an inflection in the temperature curve is reached, known as the main thermocline, that separates the warm surface water from the deeper cold waters. At about $500 \mathrm{~m}$, the temperature and phase boundary curves cross; from there downward, temperatures are cold enough and pressures high enough for methane hydrate to be stable in the ocean. This intersection occurs at shallower points in colder, 


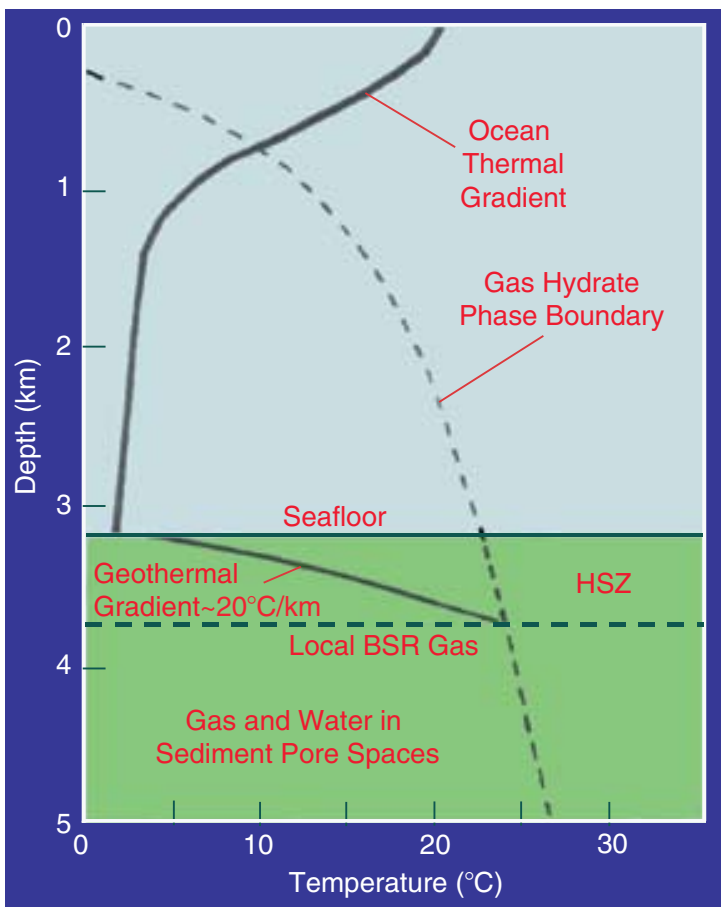

Figure 5. Methane hydrate stability zone in the ocean sediment. Note: HSZ, hydrate stability zone; BSR, bottom simulating reflection below which hydrates will dissociate into methane and water.

arctic waters. Many estimates of the global amount of gas hydrate varying by more than two orders of magnitude have been made. A consensus value of $21 \times 10^{15} \mathrm{~m}^{3}$ is estimated to be midway between the extremes. ${ }^{5}$

Methane accumulates in continental margin sediments probably for two reasons. First, the margins of the oceans are where the flux of organic carbon to the seafloor is greatest because oceanic biological productivity is highest there and organic deposits from the continents also collect along the margins. Second, the continental margins are where sedimentation rates are highest. The rapid accumulation of sediment serves to cover and seal the organic material before it is oxidized, allowing the microorganisms to use it as food and form the methane that becomes incorporated into gas hydrate. Thus, the best places to locate gas hydrate deposits for methane extraction are along the continental slopes.

The future of gas hydrates as an energy resource depends on a number of factors, including geological studies to identify concentration sites and settings where methane can be effectively extracted from gas hydrate, engineering studies to determine the most efficient means of dissociating gas hydrate in place and extracting the gas safely, economic analyses for the extraction of gas from conventional reservoirs, and geopolitical issues related to energy security. Scientific and technological challenges with respect to seismology, geochemistry, electromagnetics, heat flow, micro- and macrobiology, and drilling technology in ocean sediments must also be addressed. Successful use of this energy resource depends on government and industry investments in research and development. With concerted efforts in these areas, methane from Canadian and Alaskan permafrost regions and from the Nankai Trough could optimistically be extracted in as few as 10 years.

\section{Acknowledgments}

The author acknowledges useful discussions with W. Dillon, R. Coffin, D. Hardy, J. Gettrust, and S. Gill.

\section{References}

1. P. Villard, C. R. Acad. Sci. 106, 1602 (1888).

2. E.G. Hammerschmidt, Ind. Eng. Chem. 26, 851 (1934)

3. T.Y. Makogon, Gazov. Promst. 5, 14 (1965).

4. T.S. Collett, in "1995 National Assessment of United States Oil and Gas Resources on CD-ROM: U.S. Geological Survey Digital Data Series 30," D.L. Gautier, G.L. Dolton, K.I. Takahashi, K.L. Varnes, Eds. (1995).

5. K.A. Kvenvolden, in Natural Gas Hydrate in Oceanic and Permafrost Environments, M.D. Max, Ed. (Kluwer, Dordrecht, The Netherlands, 2000), p. 9.

\section{Organic Microelectronics and Optoelectronics Workshop IV} A Joint Workshop of ACS / IEEE / MRS

\section{July 7-IO, 2008 - San Francisco Marriott • San Francisco, CA, USA}

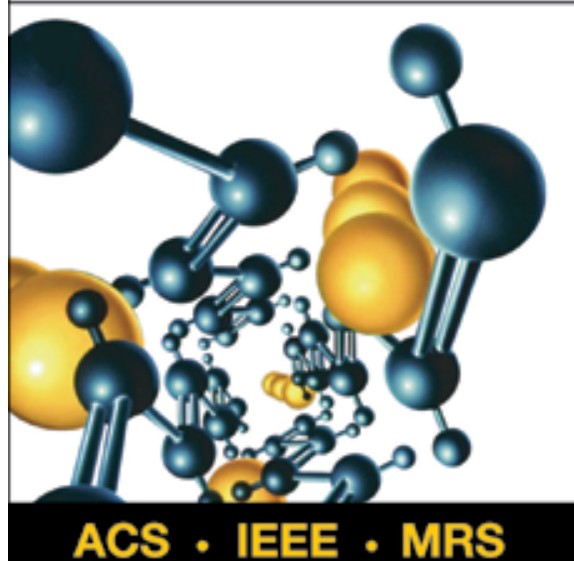

CONFERENCE CHAIRS

Edwin Chandross (General Chair), Materials Chemistry LLC

Zhenan Bao, Stanford University

Paul Blom, University of Groningen

Vladimir Bulovic, Massachusetts Institute of Technology

Duncan Stewart, Hewlett-Packard Laboratories

Register by May 23, 2008 and SAVE!

ACS, IEEE or MRS Member

$\$ 650$

After May 23, 2008

Non-member

$\$ 750$

$\$ 850$

Invited Speaker

$\$ 450$ 
